\title{
Entre a bomba atômica e os crimes de guerra: o negacionismo e a historiografia japonesa em perspectiva
}

\author{
Between the Atomic Bomb and the War Crimes: \\ Denialism and Japanese Historiography in Perspective
}

Mario Marcello Neto*

\section{Resumo}

Este artigo propõe uma discussão sobre o negacionismo dos crimes de guerra cometidos pelo Estado japonês durante a Segunda Guerra Sino-Japonesa, tendo em vista a complexa relação entre a historiografia japonesa sobre os crimes de guerra cometidos pelo país e as mobilizações negacionistas. Concluo que as narrativas acerca das bombas atômicas lançadas sobre o Japão são utilizadas tanto como forma de legitimar o discurso negacionista (ideia de vitimização), quanto para corroborar com uma historiografia engajada (que em nada anistia o Estado japonês) que pretende compreender o passado em sua complexidade, sendo o Japão vítima e algoz, a depender do contexto e dos sujeitos/instituições envolvidos. Busco, assim, analisar como a historiografia japonesa responde aos negacionismos partindo de lógicas e práticas que entendem a narrativa sobre o passado a partir de uma visão não maniqueísta entre vítima e algoz. Palavras-chave: Negacionismo; Japão; Crimes de guerra; Historiografia japonesa.

\section{Abstract}

This paper proposes a discussion on the denial of war crimes committed by the Japanese state during the Second SinoJapanese War, considering the complex relationship between Japanese historiography about war crimes committed by Japan and the negationist mobilizations. We conclude that the narratives about the atomic bombs dropped on Japan are used both as a way to legitimize the negationist discourse (the idea of victimization), and to corroborate with an engaged historiography (which in no way amnesty the Japanese State) that intends to understand the past in its complexity, being Japan victim and executioner, depending on the context and the subjects/ institutions involved. Therefore, I seek to analyze how Japanese historiography reacts to denials based on logics and practices that understand the narrative about the past from a non-Manichean view between victim and executioner.

Keywords: Denialism; Japan; War Crimes; Japanese Historiography.

\footnotetext{
* Universidade Federal do Rio Grande do Sul (UFRGS), Porto Alegre, RS, Brasil. mariomarceloneto@ yahoo.com.br <https://orcid.org/0000-0002-6493-6487>
} 
ApresentaÇão: A Historiografia Japonesa e A BOMbA ATÔMICA

Isso é um tabu, e poucos historiadores japoneses o tocam. Não podemos apenas protestar que somos vítimas inocentes da bomba sem expiar os crimes que o Japão cometeu. As lágrimas que derramam para as vítimas das bombas atômicas também devem ser acompanhadas de orações para aqueles que foram vítimas dos atos criminosos do Japão durante a guerra (Tsuyoshi Hasegawa, 2019). ${ }^{1}$

A análise que apresento neste artigo é um estudo sobre a história da historiografia japonesa em relação à bomba atômica. Realizo uma reflexão a respeito das implicações éticas e políticas desse fazer historiográfico, principalmente no que concerne ao dilema de se falar do Japão ou como vítima (bomba atômica), ou como algoz ("mulheres de conforto" e "massacre de Nanquim"), bem como os dilemas que dizem respeito ao negacionismo inerente a esses tópicos.

Compreendo o esforço realizado aqui como um exercício de história da historiografia analítica da historicidade, como propõe Valdei Lopes (Araújo, 2013). Nesta perspectiva, o autor argumenta, a partir da retomada do conceito de historicidade de Heidegger, que se deve levar em conta que: "a analítica da historiografia teria como objeto próprio pensar as diferentes formas de acesso ao passado e como a experiência histórica revelada nesses momentos pode ser atingida por uma investigação das formas de continuidade e descontinuidade, isto é, de transmissão" (Araújo, 2013, p. 41). Nas páginas a seguir, tentarei demonstrar como essa historicidade é construída pela historiografia japonesa sobre a bomba atômica, buscando compreender como as culturas de passado interpretaram e mobilizaram narrativas sobre esse passado como pautas importantes para questões políticas e identitárias de determinado contexto.

É preciso destacar que não busco esgotar o debate nestas linhas que seguem, nem estabelecer posições definitivas. Este debate poderia ser analisado a partir de uma perspectiva específica do Gender Studies, porém, o foco aqui é compreender as relações entre a historiografia japonesa e os negacionismos em determinados contextos, portanto, o necessário debate da emergência da 
mulher como um sujeito histórico capaz de narrar e historicizar seu passado não será o foco deste texto. Proponho um debate sobre dois aspectos fundamentais: 1) como uma historiografia voltada a legitimar o Estado-nação se vê encurralada ao tratar de passados traumáticos de colonização/dominação/ exploração entre países diferentes, ou seja, como a historiografia japonesa (em sua heterogeneidade) reagiu às demandas internacionais e dos movimentos sociais japoneses, ocorridas a partir da década de 1980, por reconhecimento e aprofundamento, tanto no que diz respeito às pesquisas sobre a responsabilidade do imperador com relação aos crimes de guerras cometidos em nome dele, quanto às ações de negacionismo praticadas em defesa de um passado japonês moralmente superior e inviolável; 2) compreender como os usos e as construções de determinadas narrativas sobre eventos do passado são erigidos e mobilizados no presente, propondo não só uma nova interpretação, mas atribuindo um senso de justiça à memória. Ou seja, como a bomba atômica foi utilizada por diferentes discursos para justificar uma postura política e ética com relação às tensões citadas no item anterior.

\section{"Mulheres de Conforto": entre o Negacionismo E o FAlsário}

Antes do início formal da Segunda Guerra Mundial, em 1939, os crimes de guerra japoneses eram denunciados. Essas denúncias afetaram a própria produção historiográfica, em um contexto de alta censura e violência, durante a Era Showa, nas décadas de 1930 e 1940. Um dos primeiros crimes (ainda não classificado como crime contra a humanidade) a ser considerado como perpetrado pelo império japonês é o chamado "mulheres de conforto". Antes de tudo, é preciso compreender a própria historicidade do termo. Utilizado para definir práticas de escravidão e servidão sexual de mulheres aos soldados japoneses, este nome deriva de uma concepção machista, normalmente utilizada em anúncios para atrair as futuras vítimas.

O uso das "mulheres de conforto", argumenta Yuki Tanaka (2001), trata-se de uma prática deliberada e organizada desde 1910, de deslocamento e confinamento de mulheres (a grande maioria coreanas, mas também chinesas, filipinas e, em menor número, japonesas ou coreanas residentes no Japão em virtude da colonização, dentre outras) para que fossem alvos de abusos sexuais pelos soldados japoneses. Pesquisas mais recentes (Yoshimi, 2002) apontam 
que grande parte dessas mulheres eram capturadas por anúncios mentirosos que ofereciam trabalho (com um salário fixo, em contexto de guerra) em troca de serviços domésticos. Yoshimi (2002) alerta que muitas eram adolescentes e não sabiam ler, portanto, os anúncios serviam apenas como armadilhas para enganá-las e aprisioná-las.

No entanto, o surgimento desse crime sistemático e organizado passa por um crivo patriarcal em torno do tema. O termo "mulheres de conforto" é considerado pejorativo para definir a exploração sexual de mulheres, rejeitado por muitas vítimas e, embora seja muito usual por parte da historiografia especializada, não o utilizarei mais a partir daqui. Quando for me referir a esses crimes, irei tratá-los como "práticas de escravidão sexual", considerando que o ato de nomear tem um poder importante na legitimação ou não de determinadas práticas. Além disso, essa prática de escravidão sexual era realizada pelo império japonês desde a Era Meiji, e foi intensificada com as guerras do fim do século XIX e início do século XX.

O costume, argumenta Yoshimi (2002), foi completamente alterado e ampliado. Sua escala, na Segunda Guerra Sino-Japonesa, não permite estabelecer parâmetros com o que existia antes, tamanha a discrepância no que diz respeito à quantidade, durabilidade e brutalidade com que tais atos foram realizados. A justificativa dessa prática de confinamento de mulheres para a escravidão sexual não advém de uma moralidade contrária ao estupro, pois haveria um pagamento, um certo ato consensual. Pelo contrário, argumenta Yoshimi (2002), tratou-se de uma política que buscou impedir a disseminação de doenças sexualmente transmissíveis, principalmente a sífilis. Ao confinar estas mulheres, os soldados teriam a segurança de não serem contaminados. Devido à duração da guerra, de 1937 até 1945, e à ocupação de vários territórios além dos limites do Japão, o número de mulheres exploradas sexualmente foi muito grande. A exatidão desses números é fruto de um debate que em breve tratarei.

Uma das questões centrais tratadas por Yoshimi (2002) é saber se o imperador e o alto comando japonês tinham consciência destas práticas de exploração sexual. O historiador supracitado encontrou fontes de que o tio-avô de Hirohito, o Príncipe Kan'in Haruhito, foi um de seus organizadores em Shangai. Além disso, o exército japonês confeccionou uma série de documentos regulamentando-a. Desde dias e horários permitidos, o salário a ser pago 
(algo que, segundo comprovado, não foi realizado na maioria dos casos) e até mesmo a proibição de armas e álcool nos estabelecimentos. O autor ainda comenta sobre a organização do exército imperial no que diz respeito às práticas de morte voltadas às mulheres que adoeciam, à pausa durante o ciclo menstrual, entre outras questões. A Kempeitai, polícia secreta japonesa, ficou a cargo da maioria destes recrutamentos forçados, seja com propostas enganosas, seja pelo uso da força (Yoshimi, 2002).

De forma sucinta, esta prática descrita acima, violenta, cruel e machista, não foi uma novidade para os asiáticos, que já vinham denunciando coisas semelhantes desde o início do século XIX. A prostituição no Japão, durante a década de 1930, era legalizada, ou seja, era permitida por lei desde que houvesse contribuição tributária. O Japão tornou-se alvo de turismo sexual, seja de países asiáticos ou de comerciantes e visitantes estrangeiros (Sanders, 2006). A problemática da exploração sexual de mulheres por parte do Japão, nas décadas de 1930 e 1940, embora muito maior e mais violenta, não só não chocou a comunidade internacional como foi utilizada (com a desculpa de se tratarem de prostíbulos) pela ocupação aliada no país até o fim de 1945, classificando-se esses espaços, a partir de 1946, de forma velada, como cafeterias ou casas de shows. Isso gera outro debate mais profundo, que a historiografia vai enfrentar, acerca da diferença existente entre a prostituição e a exploração sexual forçada - partindo-se, num caso, da premissa da voluntariedade e do consenso, e noutro, da escravização e da obrigação.

Yoshimi (2002), ao pesquisar em diversos acervos, na China, Japão, Austrália e Filipinas, mapeou que foram criados em torno de dois mil prostíbulos (casas em que estas mulheres ficavam para serem escravizadas sexualmente), e o número de mulheres violentadas ficaria em torno de, no mínimo, 50 mil, podendo extrapolar o número de 200 mil mulheres, uma vez que o governo Showa, e a posterior censura aliada ao Japão, destruíram muitas fontes oficiais necessárias para a contabilização. O estigma social causado nessas mulheres faz com que muitas vítimas não tenham coragem de assumir o fato publicamente, o que deixa esse número ainda mais impreciso (Chang, 1997).

Essa imprecisão é característica comum da pesquisa histórica, como argumenta Vidal-Naquet (1988). Quando se tratam de crimes em que os agentes causadores do dano fazem parte do Estado, as políticas de produção documental, acesso à informação e arquivamento são completamente esvaídas. Por isso, 
pode-se dizer que uma pesquisa eticamente comprometida, em contextos como o referido acima, dificilmente consegue estabelecer certezas numéricas com relação às vítimas e aos danos.

Um dos historiadores que mais se destacou, tanto no ambiente universitário quanto na esfera pública, é Ikuhiko Hata (1986). Um negacionista que iniciou sua trajetória de pesquisa com relação à exploração sexual de mulheres, por parte do Japão, a partir da invalidação de testemunhos que comprovavam a existência sistemática dos casos. Seu principal argumento era de que o governo coreano colaborou com a criação de prostíbulos, mas que estes eram frequentados pelos militares particularmente, sem nenhum sistema organizado, muito menos com anuência do imperador. Hata doutorou-se na University of Tokyo, e parte considerável de sua carreira foi feita como historiador do Ministério das Finanças do Japão. Sua ligação institucional pode ser vista como uma relação quase servil. Para além da simples negação, o seu argumento concentrou-se no questionamento da validade das fontes e dos testemunhos.

Na década de 1960, um jornalista encontrou imagens, em livros de fotografias sobre a Segunda Guerra Mundial, que teriam sido captadas nos lugares onde essas mulheres foram submetidas à exploração. Kakou Senda (1973) publica, em 1962, um livro em que resolve investigar quem eram aquelas mulheres. Descobre elementos importantes sobre a escravização sexual do exército japonês, principalmente a partir de entrevistas a vítimas e a soldados japoneses. Seu livro, chamado Mulheres de Conforto Militar ${ }^{2}$, foi bastante aclamado pelo universo acadêmico, tendo uma recepção bastante mais discreta pelo público em geral. Ganhou um filme homônimo em 1974, dirigido por Takamori Ryuichi - filme que também teve discreta aceitação, porém, academicamente acendeu uma fagulha memorial importante para o debate historiográfico.

Ainda neste sentido, Seiji Yoshida (1977) estabeleceu um relato de extrema importância para a historiografia do tema. Corroborando a tese de que a memória suscita questões para a história, percebe-se que, mesmo com todas as tentativas, é impossível soterrarem-se completamente as memórias dissidentes da versão oficial; algum vestígio sempre permanece. Seiji, que depois da guerra filiou-se no PCJ, ganhou a vida como escritor, tendo-a vivido, em parte, na Coreia; apenas retornando ao Japão em 1947. Até 1977, era desconhecido do grande público. Porém, é neste ano que publica um livro supostamente de memórias, intitulado Mulheres de conforto coreanas e o povo japonês ${ }^{3}$ 
(Yoshida, 1977). O sucesso do livro é estrondoso, inclusive na Coreia do Sul, lugar onde a maior parte das vítimas desse crime se concentrava. Aproveitando este sucesso, Yoshida (1983) publica a continuação de suas memórias em Meus crimes de guerra: O transporte forçado de coreanas 4 , em 1983.

Ambos os livros relatam a participação de Seiji Yoshida em uma posição de extrema legitimidade, como algoz. Durante parte considerável da década de 1970 e 1980, Yoshida publica uma série de relatos sobre sua experiência, apresentando-se como alguém que colaborou para a escravização sexual de coreanas, todavia, que estava arrependido e, principalmente, denunciava, tendo em vistas o restabelecimento da verdade. Parte importante dessas reportagens (Yoshida, 2014) foi publicada no jornal de grande circulação no Japão Asahi Shimbun. Além disso, ele volta à Coreia do Sul, torna-se palestrante e divulga os horrores concernentes a esse crime sobre o qual não se falava (Askew, 2004).

A narrativa memorial de Seiji Yoshida é tão importante que o relatório da ONU referente às "mulheres de conforto", organizado por ativistas dos direitos humanos, publicado em 1996, tem como uma das suas bases argumentativas os seus relatos. Ainda em 1996, depois de muito ser questionado por incongruências entre os seus dois livros, e por não haver registros de alguns fatos narrados por ele (como o aprisionamento de mulheres de uma fábrica em uma cidade pequena na Coreia do Sul), Ikuhiko Hata (1986) tem um papel fundamental na deslegitimação do relato de Seiji Yoshida. Hata denuncia as discrepâncias factuais entre o que Yoshida apresentava e o que as fontes permitiam dizer. Tal pressão leva Seiji Yoshida a admitir que seus livros não eram memórias, mas apenas "ficções".

Seu relato é extremamente emotivo, fundamentado do ponto de vista cronológico e contextual. Tudo o que ele relata faz sentido, é crível. No entanto, suas narrativas são tão confusas quanto a sua história pessoal. E, mesmo demorando décadas para admitir a sua farsa, em um de seus relatos ele dizia, por exemplo, ter estudado numa determinada escola, algo que Hata (1986), a partir da simples verificação de dados escolares, descobriu não ser verdade. Tal atitude de Yoshida inaugurou uma era de legitimação aos negacionistas.

Yoshida, antes de admitir sua farsa, possibilitou uma gama gigantesca de relatos sobre o caso. Embora parcela importante da sociedade japonesa tenha se voltado contra ele, como aponta a reportagem do Japan Times (The Asahi 
Shimbun, 2014), desde 1977, com o seu primeiro livro e a série de reportagens publicadas por um jornal de ampla circulação, Seiji tornou-se o porta-voz de uma vergonha nacional. Ele, na condição de representante do Estado na posição de algoz, assumiu o papel de pedir desculpas pelos seus atos (Askew, 2004).

$\mathrm{O}$ impacto da sua narrativa foi tão grande que a pressão internacional obrigou os EUA, no início da década de 1990 a liberar para pesquisa os seus arquivos militares sobre o período de ocupação no Japão. É assim que Yoshiaki Yoshimi (2002), citado anteriormente, consegue comprovar a relação entre o império japonês e a prática de escravização sexual. Desta forma, quando o público fica sabendo que Yoshida estava forjando uma memória que não existia, os historiadores, que já apontavam esses crimes havia décadas, conseguem comprovar, por uma gama de fontes inéditas, aquilo que alertavam anteriormente.

Além disso, embora o relato de Seiji Yoshida fosse falso, ele permitiu o surgimento de diversos outros relatos verdadeiros. Vale pensar que, justamente por não ter participado do crime, ele não havia recalcado esta narrativa sobre seu passado, podendo, desta forma, discutir o assunto livremente. Porém, sua fala não é uma mera invenção, permitindo-lhe construir uma narrativa totalmente verossímil, malgrado os personagens (incluindo ele mesmo) não existissem historicamente. Isso motivou o secretário-chefe de gabinete Yohei Kono a pedir formalmente desculpas à Coreia do Sul, dois dias antes das rememorações em Hiroshima, em 1993.

O agosto simbólico do passado japonês é certamente algo interessante de se perceber. Entre outras coisas, Yohei Kono, em seu discurso, reconhece a culpa do Japão e do imperador no processo de coerção e servidão sexual das mulheres. Hata (1999) foi um dos primeiros a investigar e buscar erros e mentiras no discurso de Kono. A queda do Primeiro-Ministro japonês, ainda em agosto de 1993, de cujo governo Kono fazia parte, impediu um pedido formal de desculpas por parte da autoridade máxima, ficando tal pedido restrito a um representante. Depois disso, os governos conservadores de direita no Japão nunca mais cogitaram realizar este pedido, que parecia tão próximo na década 1990.

Conformadores do passado, presentes em universidades japonesas como professores, passaram a abandonar seus clássicos temas de pesquisa e a se dedicar a estudar o que chamavam de "mulheres de conforto", para defenderem a coesão do seu passado completamente fraturado e em disputa. Porém, os que mais tentaram aproveitar este contexto para problematizar foram os 
historiadores, principalmente aqueles dedicados a uma pesquisa séria, eticamente engajada no que diz respeito à vida e aos direitos humanos, os quais eram contrários a posturas do imperador durante a guerra e buscavam constatar os culpados e responsáveis pelas bombas atômicas. Por isso, nomes já atuantes, como Yuki Tanaka (2011), Tsuyoshi Hasegawa (2009), Yoshiaki Yoshimi (2002), entre outros, começam a problematizar outras questões, além do processo de escravidão sexual. Ao fraturarem a ideia consolidada de um império sólido, justo e leal, no qual os criminosos seriam apenas alguns militares - casos pontuais que já teriam sido punidos -, poderiam intervir ainda mais no debate; no questionamento da memória pública do Japão enquanto vítima. Por isso, os produtores de história supracitados começam a pautar discussões sobre como a bomba atômica estava sendo utilizada num processo fundamental de anistia ao imperador Showa (já falecido neste contexto, mas cuja memória era, então, questionada).

A década de 1990, no Japão, é marcada por esta ruptura. Movimentos sociais e alas conservadoras se mobilizam de todas as formas, em uma guerra de história e de memória que até hoje está em andamento. Em um texto publicado no Japan Times (KOIKE, 2014), a ex-ministra da Defesa Yuriko Koike afirma: "Mas é claro que ninguém se beneficiará de uma nova rodada de um acalorado debate histórico. Para evitar isso, são necessários líderes políticos como De Gaulle e Adenauer" (traduzimos e grifamos) ${ }^{5}$. Depois, ao continuar explanando sobre a sua visão de democratas liberais em relação aos governantes da França e da Alemanha Ocidental, conclui: "somente quando pudermos discutir o passado sem pôr em risco o futuro é que os países do nordeste da Ásia poderão estabelecer uma estrutura de paz verdadeiramente durável" (traduzimos) ${ }^{6}$.

Essa oração que grifei no discurso de Koike, em 2014, explicita as questões que a memória impõe à historiografia. Isso implica, diretamente, em se compreender uma acepção dupla: só é possível questionar-se a postura do imperador e os crimes de guerra do Japão se, por outro lado, se considerar que a bomba atômica tem servido como um bode expiatório para políticas nefastas, sobretudo de dominação na Ásia, como a própria ex-ministra deixa transparecer ao final de sua fala.

Como aponta Tanaka (2011), esse passado cristalizado e homogêneo precisa ser esfacelado para a construção efetiva de uma democracia, para que se faça justiça às vítimas, aos descendentes de criminosos que não sabem que o 
são e ao povo japonês, que não consegue conviver com este trauma de maneira saudável, causando a sua repetição e atuação constante. Desde Yoshida, em 1977, até Koike, em 2014, os contextos mudaram completamente, mas a busca pelo passado idealizado segue a mesma. O que mudou nesses 37 anos, substancialmente, foi a historiografia. Os discursos negacionistas ainda ocupam espaços significativos na academia, questão que veremos a seguir. No entanto, posições críticas a essa postura são muito mais aceitas, internacionalizaram-se e complexificaram o debate.

Destarte, a farsa de Yoshida é utilizada como estratégia de deslegitimação de todas as testemunhas e todos os historiadores, que confirmam não só a existência pretérita das práticas de servidão sexual por parte do império japonês, como corroboram a tese de anuência do imperador e da alta cúpula. Esse grupo negacionista não é maioria nas universidades japonesas, mas tem bastante respaldo na sociedade civil. Vale ressaltar que, partindo da ideia proposta por Mateus Pereira (2015) ao analisar o caso da memória da ditadura civil-militar brasileira, se houve uma possibilidade de inscrição frágil na memória coletiva japonesa com relação às práticas de servidão sexual anteriores à descoberta da farsa de Yoshida, essa se desfez rapidamente quando o caso veio à tona. Isso leva a crer que a inscrição frágil não tinha acontecido, tratando-se de um movimento de transição que não conseguiu completar seu rumo. ${ }^{7}$

Por outra via, quando Seiji Yoshida assume ter ficcionalizado sua memória, tem-se uma mobilização social muito grande em torno disso, buscando não só a deslegitimação da sua obra e do seu legado, como a busca por indenizações contra o Asahi Shimbun, por ter veiculado suas memórias e, junto com tudo isso, a descrença generalizada pela historiografia então produzida. Muito antes do debate sobre fakenews, no Japão acentuou-se a ideia de se investigarem historiadores, levantando-se detalhes e erros, tendo o investigador por intuito arvorar-se como portador de uma moral e técnica superiores, que o permitiam defender sua tese central.

O uso do fazer historiográfico, ou seja, o rigor das fontes como única discussão possível, não dá conta de responder os questionamentos da memória e suas complexidades. É necessário um claro debate ético e político sobre o passado, ao contrário do que estabelece a ex-ministra. É preciso, compreender que erros pontuais são comuns a qualquer produção historiográfica. Isso não tem 
relação alguma com invalidações de fontes e testemunhas por critérios rasos, como, por exemplo, "são chineses e querem prejudicar o Japão", entre outros.

Este debate, e as tensões geradas com relação à exploração sexual das mulheres, é um dos vários topoi da historiografia japonesa que dificultam falar-se amplamente sobre a bomba atômica. Antes de se ver como vítima, parece ser necessário ser visto (internamente, pela população japonesa) como algoz. É preciso, neste ponto de vista, escancararem-se as feridas históricas para a construção de uma memória justa ricoeuriana. Para um país com a tradição do bushido, pautada, sobretudo na lealdade e na honra, o exército imperial é acusado (algo fartamente comprovado) de crimes em temáticas condenadas socialmente e recalcadas como tabus sociais públicos; o que não significa que não sejam praticados no ambiente privado. Todas as práticas de crimes cometidos pelo exército imperial derivam de estupro coletivo, mutilação e massacre, canibalismo e animalização dos prisioneiros de guerra. Nenhuma das características do bushido pode ser percebida aqui.

Partindo da leitura de Conrad (2010), de que o imperador Showa é uma continuação do projeto Meiji, que, por sua vez, não rompe completamente com as tradições feudais de hierarquia, lealdade e respeito, faz-se necessário compreender-se que uma acusação de exploração sexual poderia ser admitida ou imputada a uma ou outra pessoa e, com isso, resolver-se-ia em termos o problema, pois não seria necessário responsabilizar-se o Estado, nem mesmo punir-se a família imperial. No entanto, reconhecer a existência dos crimes, independente de quem os cometeu, significa assumir uma postura não tradicional de tempo e admitir que os costumes e a cultura são fluídos. E isso implica compreender que as interpretações do passado são dinâmicas e atendem a demandas do presente, desfazendo-se biografias alicerçadas na exploração alheia e confrontando-se estruturas de poder já estabelecidas.

\section{MASSACRE DE NANQUIM: A HISTORIOGRAFIA,} A NEGAÇÃO E A MORALIDADE EM DISPUTA

Um dos casos mais latentes sobre os crimes de guerras japoneses é o chamado "Massacre de Nanquim", ou "Estupro de Nanquim". Diferentemente do que ocorrera com a exploração sexual de mulheres, o caso de Nanquim foi filmado, registrado, denunciado e houve algumas punições logo no pós-guer- 
ra, o que dá ao caso outra dinâmica. O Massacre de Nanquim, segundo Iris Chang (1997), foi um evento que durou em torno de seis semanas, iniciado em dezembro de 1937, durante a Segunda Guerra Sino-Japonesa, quando os japoneses chegaram à cidade em questão, à época a capital da China, e iniciaram um processo de rendição, desarmamento e homicídios de chineses. Estima-se que mais de 300 mil chineses foram mortos, sendo muitos deles mulheres, que foram estupradas, e vários foram mutilados, antes e depois de sua morte. Grande parte dos altos oficiais envolvidos neste episódio foram julgados pelo Tribunal Militar Internacional para o Extremo Oriente, ou pelo Tribunal de Crimes de Guerra de Nanquim, criado especialmente pela China para julgar crimes praticado contra os chineses.

O missionário católico estadunidense John Magee vivia em Nanquim em 1937, e gravou cerca de duas horas de vídeo sobre esses acontecimentos (The Nanking Massacre...). Após a Segunda Guerra Mundial, ele foi uma testemunha-chave para a condenação dos culpados. Essa condenação, indiretamente, transmitiu a ideia de organização do passado por parte do Japão, sem que se precisasse questionar, pois, se houve crime, ele já teria sido julgado. Por isso, os estudos que apontam a culpa da família imperial neste processo são fundamentais, pois a busca de justiça passa pelo estabelecimento da responsabilidade daqueles que a têm, para que a culpa seja imputada pelas instituições competentes (Vidal-Naquet, 1988).

No entanto, o caráter anistiador e, portanto, amnésico, da rendição incondicional, é o perdão à família real. Com isso, anistiou-se o príncipe Asaka, tio de Hirohito e comandante das tropas em Nanquim, ou seja, o principal responsável por tudo que foi praticado ali (Chang, 1997).

Segundo Iris Chang, já em 1938 representantes do governo chinês na Liga das Nações denunciaram as atrocidades japonesas, considerando-as abusos, mesmo em tempos de guerra. Ainda neste ano, argumenta a autora, o Partido Comunista Chinês, isolado nas montanhas organizando sua guerrilha, também produziu manifestos contrários ao que foi feito pelos japoneses em Nanquim. Saburo (2000) alerta que, ao longo das décadas seguintes, os livros didáticos do Japão, produzidos por historiadores, tinham problemas devido à nomenclatura (massacre, estupro, invasão, conflito de Nanquim) e ao grau de informação que traziam (número de mortos, tipos de crimes etc.), demonstrando, mais uma vez, que o passado japonês, estruturado segundo uma nar- 
rativa uníssona e estável, não pode ser questionado, sob o risco de a lei ser usada contra quem ousa interferir. Isso nem sempre se concretiza, mas a relação desigual de forças que impõem uma censura faz com que muitos historiadores prefiram não estudar esta temática.

É preciso destacar-se, também, que Harold Timperley (1938), jornalista estadunidense, cobrindo a China em 1937, registra por telegrama a situação vivida pelos chineses em Nanquim, quando da invasão japonesa naquele ano. Ele publica, em 1938, o livro What War Means, no qual apresenta entrevistas, percepções e alguns documentos que conseguiu obter para discorrer sobre este período. Estas versões recentes do massacre, principalmente no Ocidente, foram levadas ao esquecimento com o advento da Segunda Guerra Mundial e, posteriormente, a descoberta do Holocausto. No entanto, argumenta Chang (1997), conforme a Europa foi se estabilizando, os conflitos sociais na China foram minorando, tornando-se possíveis outras visões mais amplas do ocorrido em Nanquim.

Em 1965, o soldado japonês Ikkaku Shimono (1966) publica o livro A Verdade da Estratégia de Nanquim - Registro de Guerra da Sexta Divisão de Kumamoto, no qual se propõe a falar "a verdade", a única possível, na sua visão, descrevendo os crimes de Nanquim como banalidades da guerra e defendendo a teoria de que os chineses eram ainda mais cruéis. Este é um caso em que a memória interfere e traz questionamentos à historiografia, não só memórias subalternas, mas memórias que tentam legitimar e justificar atrocidades recalcadas, silenciadas e anistiadas. Essas memórias, quando retornam à arena pública, mobilizam historiadores a reagir e complexificar o debate.

Tomio Hora (1982) publica um livro, em 1967, sobre o chamado "concurso dos 100 ", segundo o qual dois soldados japoneses teriam competido para ver quem matava 100 chineses primeiro em Nanquim. Tal história, que mais parecia uma lenda espartana, acabou sendo confirmada por Hora, através de entrevistas e registros deixados por soldados e oficiais sobre os dias na cidade. Tal evento foi questionado de diversas formas. Uma delas alegava que era mentira, que o concurso não havia ocorrido, visão completamente negacionista que era liderada por historiadores como Hata (2018). Outros historiadores mais conservadores diziam que se tratava de um ato isolado, sem ampliação geral desta prática para outros casos; sendo assim, não se trataria de um massacre, mas de um desvio de conduta de dois soldados em meio a combatentes íntegros que haviam 
lutado bravamente em um contexto de guerra, em que a lógica é matar ou morrer, desta forma não teriam cometido crime algum.

Esse argumento é facilmente descontruído por ser uma mentira, sem sustentação ética ou empírica. As filmagens (mais de uma hora), realizadas pelo missionário estadunidense John Magee e divulgadas para o mundo inteiro em 1946, a partir da atuação do TMFE e do Tribunal de Nanquim, trazem elementos suficientes para a comprovação de que não se tratavam de ações isoladas. Isso, sem se mencionarem as inúmeras outras fontes e testemunhas deste processo. Nestes julgamentos, entre outros condenados, os soldados do concurso dos 100 foram mortos depois de serem criminalizados perante o juiz do tribunal.

Em seu livro intitulado Massacre de Nanquim ${ }^{8}$, Hora (1982) refuta as teses negacionistas sobre o massacre. Baseando-se em fontes chinesas e japonesas, estabelece uma narrativa contundente em demonstrar os atos de crueldade deliberadamente praticados pelo exército e por soldados japoneses. Alega que as autoridades não só sabiam da existência deles, como incentivavam ou fingiam ignorar a sua existência, anuindo com o que estava sendo feito. Esta percepção do passado japonês foi muito bem aceita na China, na qual as marcas são diferentes dos casos das escravizadas sexualmente. $\mathrm{O}$ estigma da sobrevivente que foi abusada sexualmente é completamente constrangedor na sociedade, torna-se muito mais difícil a obtenção de testemunhos. Ver o estupro acompanhado de morte gera revolta, e, com isso, pode-se denunciar como uma forma de redenção e expiação do mal afligido. Um senso de justiça está no ato de se narrar a dor alheia que foi observada, bem como uma certa desculpa (no sentido de se tirar a culpa) por não se ter impedido a morte ou a violência extrema de alguém (Lifton, 1967).

Tokushi Kasahara (1997) é um historiador conhecido por suas pesquisas contundentes sobre o Massacre de Nanquim, iniciadas na década de 1980. O autor estima que tenham sido mortas, mutiladas e estupradas mais de 100 mil pessoas (talvez o dobro, uma vez que a mesma imprecisão citada para o caso de exploração sexual se encaixa aqui), em um período de seis semanas.

Kasahara (1997) foi acusado por Ikuhiko Hata (1998), o mesmo historiador negacionista com relação aos crimes de exploração sexual, de falsificar uma imagem. Ocorre que Kasahara (1997) havia retirado uma imagem de um álbum e colocou a mesma legenda contida nele, sem apurar a informação. Hata, com um discurso objetivista e empirista, acusa-o de falsificador. A editora de 
Kasahara suspende a publicação do livro, pede desculpas, confecciona uma errata e só então torna a vendê-lo (Kasahara, 1997). Hata atua no campo da objetividade quando lhe favorece, quando descobre incongruências que desestabilizam narrativas que defendam a perspectiva anistiadora e conservadora do status quo japonês. Ele busca constantemente desmoralizar e profanar biografias com o intuito de fortalecer sua argumentação. O discurso da empiria é apenas uma fachada científica atrás da qual se esconde para definir o que vale e o que está eliminado; quanto à fonte, o que é ideológico e articulação comunista, e o que é a defesa da verdade, mesmo que isso implique em defender criminosos de guerra, ignorando a existência das factualidades referenciadas por inúmeras fontes.

Assim, iniciam-se muitos debates acalorados, vários travados de forma injusta, com manipulações de fontes e alterações de citações para corroborar ideias maiores. Isso fica evidenciado nos debates realizados por Shudo Higashinakano (1998) e pela jornalista estadunidense de ascendência chinesa Iris Chang (1997) sobre o Massacre de Nanquim. Shudo Higashinakano manipula as fontes a fim de desmentir Chang, que publicara seu livro alguns meses antes, em 1997. Tratava-se de uma busca pela desmoralização acadêmica do seu "inimigo" sob argumentos técnicos: mau uso de fontes, datações incorretas, contextualizações incertas, etc. Shudo Higashinakano é um historiador formado, com mestrado e doutorado na área, professor universitário de história intelectual na Asia University of Japan. No entanto, sua área de atuação é a história intelectual alemã. $\mathrm{O}$ fato que fez com que migrasse seu interesse para o Japão da Segunda Guerra Mundial foi porque percebeu que o passado imperial nipônico, o qual deveria estar assentado sobre os pilares da honra e da valentia, era confrontado por narrativas que demonstravam (de forma objetiva, factual e eticamente posicionada) as atrocidades mais esdrúxulas possíveis, a exemplo do estupro, das mutilações e do enterramento de pessoas vivas.

Higashinakano foi processado e acabou sendo condenado por fraudar propositalmente as narrativas sobre o passado e caluniar uma testemunha do Massacre de Nanquim em seu livro (Higashinakano, 1998), depois de ver seu testemunho contemplado no livro de Chang. A vítima havia sido filmada pelo missionário católico e exercia seu ativismo, destacando e comprovando seu lugar de fala. Shudo vocifera contra a vítima, dizendo, sem qualquer critério, ser mentira que ela está no vídeo. A vítima, que era chinesa, entrou com um 
processo na Suprema Corte Japonesa, que condenou Higashinakano a pagar uma indenização de quase 40 mil dólares (Askew, 2004). O valor alto se deve à difusão que ambos os livros tiveram, tanto o de Chang quanto o de Higashinakano. Isso ocorre num contexto em que a China estava em grande crescimento econômico e tentava uma estabilização política depois das manifestações intensas de 1989 (Askew, 2004).

\section{CoNClusÃo}

Essa tensa relação discutida acima, entre a verdade factual e o negacionismo, sempre esbarra nos limites éticos de condução da pesquisa histórica pelo historiador. Essa migração de área, por si só, não significaria um embate entre a história leiga e a história acadêmica. No entanto, o seu modus operandi permite concluir que isto acaba ocorrendo. Uma vez que se desvelam, nesta seara discursiva, as matrizes disciplinares que discutem apenas as objetividades, as análises de fontes e afins não dão conta de responder os limites éticos e o respeito à vida humana. Fontes históricas nos trazem a objetividade do fato. Negá-las não pode ser apenas um ato narrativo. É preciso, para isso, um contexto comprobatório do contrário, para que a narrativa falseadora seja construída. O que Higashinakano faz é apenas a negação a partir de um discurso objetivista e acusatório, colocando todas as evidências encontradas em xeque, afinal, elas afetam diretamente a sua visão do supostamente estável e glorioso passado japonês.

O renomado historiador japonês Yuki Tanaka (2001) aborda, na década de 1980, numa de suas primeiras publicações, o tema da escravização sexual de mulheres, realizada pelo exército japonês, sob uma ótica de denúncia, uma vez que tal assunto ainda era incipiente no ambiente acadêmico. Seu livro (Tanaka, 1993) sobre os crimes japoneses cometidos na Oceania é um exemplo claro da tentativa de se denunciar esse passado silenciado e, sobretudo, pleitear uma função para os intelectuais: a de questionar a conformação do passado e o status quo.

Tanaka foi um dos primeiros historiadores a enfrentar o problema de falar sobre a bomba atômica historiograficamente e militantemente, sem ignorar os crimes de guerra cometidos pelo Japão. Tal questão pode ser percebida no livro organizado por Tanaka e Young (2009). Os artigos que compõem 
a obra realizam uma densa discussão sobre o bombardeamento contra populações civis, praticados, seja pelo exército japonês, seja pelos estadunidenses - a exemplo da bomba atômica -, dentre outros casos. Em uma situação comum, se pensarmos em outras culturas historiográficas, não haveria por que existir um dilema entre estabelecer uma lógica de complexidade e balanceamento entre um estudo crítico de eventos cruéis, esteja o Japão na função de vítima (a bomba atômica, no caso) ou na função de algoz (o massacre de Nanquim, no caso).

Isso se faz peculiar no Japão, devido àquilo que Sato (2012) chamou de peculiaridades da historiografia do leste asiático. O papel que a historiografia assumiu neste continente é semelhante ao Ocidente, a partir do século XX: de crítica ao status quo. O diferencial que deve ser destacado é a capacidade de a historiografia intervir no debate da arena pública. Por mais divulgação midiática que se tenha, a história recente do Japão, de modo geral, não é pauta de estudos, seja no ensino primário, seja nos livros didáticos. Considera-se que se deve estudar na escola, no que diz respeito às aulas de história, o "passado longínquo", morto e superado (Nozaki, 2008).

Essa questão traz uma discussão sobre a importância que a historiografia assume na sociedade japonesa. A historiografia japonesa, em geral, conforme afirma Okamoto (1993), tende a voltar suas discussões para um passado distante, normalmente atrelado ao passado medieval japonês. Dentro desse escopo de análise, questões que envolvem o processo de invasão estadunidense no Japão no século XIX, passando pela Segunda Guerra Mundial e chegando a eventos ainda mais recentes, ocupam pequenos espaços nos departamentos de história do Japão, ainda que, vale ressaltar-se, não sejam inexistentes.

Uma peculiaridade importante a se destacar é a presença de muitos historiadores negacionistas em universidades, o que torna o debate mais complexo devido à legitimidade e à liturgia do cargo a partir do qual se fala. No entanto, pesquisas a respeito de temáticas mais contemporâneas, embora marginalizadas, estão em fase de crescimento. Muitas delas motivadas por patrocínios e incentivos estrangeiros (como a coleção da Oxford sobre a escrita da história, que abarca diversas discussões a respeito da Ásia) e pela atuação de intelectuais estrangeiros como professores e pesquisadores no Japão - a exemplo de Philip Seaton (2010), da Hokkaido University, e Robert Jacobs (2016), da Hiroshima City 
University, entre muitos outros, que têm como foco de estudo questões que envolvem a memória traumática do Japão do pós-guerra.

Essa correlação de forças entre a pesquisa acadêmica - que busca compreender os meandros de um presente fragmentado e dilacerado - e uma tentativa de conformação historiográfica, voltada ao estudo do passado como um fim em si mesmo, que se distancia do presente e não se esforça por influenciá-lo, é a tensão que se deve compreender. Desta forma, aqueles que decidem além de academicamente estudar esse passado recente vão para as mídias, para os movimentos sociais e estabelecem relações com intelectuais de outras partes do globo, difundindo suas pesquisas e suas demandas sobre uma tentativa de reconciliação com esse passado. Eles contribuem, com suas pesquisas, para produções de outras memórias, mais justas (tanto juridicamente quanto narrativamente, em termos éticos).

A atuação de Yuki Tanaka, por exemplo, é uma das formas de escancaramento dessas feridas históricas, seja para os japoneses, seja para o mundo. Ao falar dos crimes de guerras cometidos pelo Japão e da necessidade de sua punição, num momento em que o movimento nuclear vem crescendo no país, muitos desses intelectuais assumem um papel importante na liderança e na resistência de parte de uma intelectualidade que nunca conseguiu conceber a produção de uma energia nuclear, sempre nociva à saúde, como uma saída coerente. $\mathrm{O}$ acidente de Fukushima, em 2011, parece ter deixado isso ainda mais em evidência. Tanaka, neste caso, é o exemplo mais claro de inconformação com o passado japonês.

Até aqui, procurei realizar uma incursão em elementos teóricos capazes de permitir a compreensão do processo de conformação do passado com experiências históricas possíveis de ser interpretadas, com relação ao Japão após a Segunda Guerra Mundial. Se a história, como Certeau (1982) apontava, é uma espécie de sepultura, o que nos cabe, como historiadores, é uma tentativa de elaborar este luto, de vingar os mortos, nos termos benjaminianos, tentando permitir que a relação das sociedades com seus passados traumáticos não seja mediada pelo trauma ou pelo seu caráter insuperável. A partir desta perspectiva, a história poderia ajudar a exorcizar o passado, demostrando que as tentativas das narrativas oficiais totalizantes são, em sua essência, favorecedoras da desigualdade, com cunho forte de afirmação de identidade e negação da alteridade. Essa exorcização do passado permite uma cisão entre passado e 
presente, fazendo com que o "passado que não passa" passe, tornando-se algo constitutivo do presente, mas não o presente por excelência.

Há uma naturalização da distância entre passado e presente - uma ideia natural de que eles são separados, mas ninguém sabe onde começam e onde terminam; uma ideia, enfim, de que eles estão apartados, como se o historiador não criasse isso, como se ele apenas observasse tal distância. No entanto, é preciso destacar que, para Certeau (1982), a história não só analisa essa distância, mas a cria. Como uma forma de perlaboração, a história ganha um "sentido etnológico e quase religioso do termo, a escrita representa o papel de um rito de sepultamento; ela exorciza a morte introduzindo-a no discurso." (Certeau, 1982, p. 106, grifo do autor). Como forma de marcar o passado, de criar um distanciamento, a história e a sua função simbólica, por entremeio da linguagem, enterra os mortos e busca dar sentido ao presente a partir do sepultamento destes.

Os casos de inconformação com o passado japonês do pós-guerra apontam elementos importantes para a promoção deste "sepultamento do passado", uma tentativa de mostrar que, para elaborar um luto, a historiografia precisa realizar um profundo trabalho de destotalizar os eventos do passado, centralizados em torno de uma narrativa única. Necessita-se de uma compreensão não maniqueísta deste passado e de uma produção analítica crítica que demande justiça aos mortos, e, na mesma medida, demande punição aos culpados. Segundo Pereira (2015), não há elaboração de luto sem que a justiça aja com rigor contra os criminosos (sejam eles os representantes do Estado ou parte da população civil).

Para Berber Bevernage (2018), o presente aponta para elementos dos passados que não foram elaborados e, por causa disso, geram problemas dentro do seu próprio contexto. Segundo o autor, esses elementos não elaborados tornam-se parte constitutiva do presente, tornando praticamente inviável a construção de uma nova temporalidade e de uma relação saudável com o passado, quando não permitem ver o passado como algo que passou e, uma vez que as suas feridas já cicatrizaram, pode-se seguir em frente. Desta forma, o problema não é mais o "passado". Trata-se, sobretudo, de como o presente vai lidar com isso.

Neste sentido, as narrativas oficiais sobre a bomba atômica tentam realizar uma espécie de superação do passado por meio do silenciamento. Para a história 
oficial japonesa, quando se trata de apontar culpados, a bomba atômica já passou, não faz parte do presente. Porém, é considerada presente quando é utilizada para justificar ações visando a proteção de determinada elite política.

A ausência de uma elaboração deste passado no presente, por mais silenciado que ele seja, sempre emergirá, causando tensões que só poderão ser resolvidas através do exercício do poder, do estabelecimento de políticas do tempo insensíveis a questões pendentes do passado, tornando terra arrasada toda e qualquer tentativa de reconciliação com esse passado traumático ou, no mínimo, doloroso.

Para Jacques Rancière (2010), em todas as sociedades há um tempo tomado como normal, que os grupos dominantes usam para realizar formas de dominação e controle. Porém, esse tempo dominante não é o único possível. Existem diversas temporalidades e formas de percebê-lo. Assim, é possível compreender que a relação estabelecida entre a forma dominante de organização temporal e as outras existentes se dá por meio de um jogo de poder e conflitos simbólicos, sendo a história oficial uma das grandes agentes que contribuem na conformação desse status quo.

Isso deixa evidente que as feridas históricas sobre o passado japonês, expostas por determinados sujeitos ou instituições sociais aqui analisadas, permitem não só a compreensão de formas possíveis de se questionar a conformação do passado recente japonês, mas também a emergência de possibilidades de se entender que toda tentativa totalizante do passado impede tanto qualquer possibilidade de conciliação com o mesmo quanto uma possível elaboração, gerando um eterno silenciamento de eventos tão importantes para compreensão da essência do ser humano.

Por isso, a historiografia japonesa sobre os crimes de guerra não pode ser percebida dissociada do seu dilema maior, que é a mensuração entre vítima e algoz; demanda que a memória impõe à história. Neste embate, os historiadores eticamente engajados estabelecem uma resistência e uma atuação capazes de sepultar e vingar seus mortos, algo que é, muitas vezes, visto como um desfavor por parte do Estado e da história oficial, que veem a bomba atômica como um entrave.

Desta forma, o estudo se concentra em compreender a dinâmica das nuances da historiografia japonesa que demandam, necessariamente, a exposição do papel do país nipônico enquanto algoz, principalmente no que diz 
respeito ao regime de escravidão sexual e ao massacre de Nanquim. Tal discussão permite que se compreendam as nuances entre a memória, o negacionismo e a mobilização de historiadores na organização de uma narrativa crítica e engajada que faça emergir a complexidade do passado japonês, ao contrário do que alguns defensores do status quo pregam.

\section{REFERÊNCIAS}

ARAUJO, Valdei de. História da historiografia como analítica da historicidade. História da Historiografia: International Journal of Theory and History of Historiography, vol. 6, n. 12, 2013, pp. 34-44.

THE ASAHI SHIMBUN. Third-Party Panel Criticizes Delay in Retracting "Comfort Women” Articles Over Yoshida Testimony. 23 dez. 2014. Disponível em: http:// www.asahi.com/ajw/articles/AJ201412230056.html. Acesso em: 1 ago. 2020.

ASKEW, David. New Research on the Nanjing Incident. The Asia-Pacific Journal, vol. 2, n. 7, 2004.

BEVERNAGE, Berber. História, memória e violência de Estado: tempo e justiça. Vitória: Milfontes, 2018.

CERTEAU, Michel de. A Escrita da História. Rio de Janeiro: Forense-Universitária, 1982.

CHANG, Iris. The Rape of Nanking: The Forgotten Holocaust of World War II. New York: Basic Books, 1997.

CONRAD, Sebastian. The Quest for the Lost Nation: Writing History in Germany and Japan in the American Century. Berkley: University of California Press, 2010.

HASEGAWA, Tsuyoshi. Racing the Enemy: Stalin, Truman, and the Surrender of Japan. Cambridge: Harvard University Press, 2009.

HASEGAWA, Tsuyoshi. What role did the atomic bombings of Hiroshima and Nagasaki and Soviet entry into the war play in Japan's decision to surrender in the Pacific War? Conversations with Tsuyoshi Hasegawa. In: YAMAGUCHI, Hibiki; YOSHIDA, Fumihiko; COMPEL, Radomir. The Asia-Pacific Journal, vol. 17, issue 18, n. 1, 2019.

HATA, Ikuhiko. Nankin gyakusatsu jiken - Kazu no kösatsu [O Massacre de Nanking: Examinando os números]. In: Gendaishi no hikari to kage [Luz e Sombra: ensaios sobre história moderna]. Tokyo: Gurafusha, 1999.

HATA, Ikuhiko. Nankin jiken - "Gyakusatsu" no közö [O incidente de Nanquim: A estrutura do "Massacre"]. Tokyo: Chükö Shinsho, 1986.

HATA, Ikuhiko. The Nanking Atrocities: Fact and Fable. Japan Echo, vol. 25, n. 4, 1998, p. 47-57. 
HATA, Ikuhiko. Comfort Women and Sex in the Battle Zone. Connecticut, EUA: Hamilton Books, 2018.

HIGASHINAKANO, Shüdo. "Nankin gyakusatsu" no tettei kenshö [Uma investigação completa do "massacre de Nanjing"]. Tokyo: Tendensha, 1998.

HORA, Tomio. Nankin jiken. Tokyo: Tokuma Shoten, 1982.

JACOBS, Robert. Domesticating Hiroshima in America in the Early Cold War. In: JACOBS, Robert et al. Images of Rupture Between East and West: the Perception of Auschwitz and Hiroshima in Eastern European Arts and Media. Heidelberg: Universitätsverlag Winter, 2016. pp. 83-97.

KASAHARA, Tokushi. Nankin jiken [O Massacre de Nanquim]. Tokyo: Iwanami Shinsho, 1997.

KOIKE, Yuriko. Putting an End to the Japan-Korea History Wars. 1 set. 2014. Disponível em: https://www.japantimes.co.jp/opinion/2014/09/01/commentary/japancommentary/putting-an-end-to-the-japan-korea-history-wars/\#.XyY3qihKjIU. Acesso em: 1 ago. 2020.

LIFTON, Robert. Death in Life: Survivors of Hiroshima. New York: Random House, 1967.

THE NANKING MASSACRE Project: Photographs and Films. Disponível em: https:// web.library.yale.edu/divinity/nanking/photographs. Acesso em: 2 ago. 2020.

NOZAKI, Yoshiko. War Memory, Nationalism and Education in Postwar Japan, 19452007: The Japanese History Textbook Controversy and Ienaga Saburo's Court Challenges. New York: Routledge, 2008.

OKAMOTO, Michihiro. Kokkyo no nai Jidai no Rekishi [História na era sem fronteiras]. Tokyo: Kindai-bungeisha, 1993.

PEREIRA, Mateus Henrique de Faria. Nova direita? Guerras de memória em tempos de Comissão da Verdade (2012-2014). Varia historia, vol. 31, n. 57, 2015, pp. 863-902.

RANCIÈRE, Jacques. The Aesthetic Heterotopia. Philosophy Today (Supplement), n. 54, 2010, pp. 15-25.

SABURO, Ienaga. Japan's Past, Japan's Future: One Historian's Odyssey. New York: Rowman \& Littlefield Publishers, 2000.

SANDERS, Holly. Indentured Servitude and the Abolition of Prostitution in Postwar Japan. 2006. Disponível em: https://programs.wcfia.harvard.edu/us-japan/publi cations/06-11-indentured-servitude-and-abolition-prostitution-postwar-japanholly. Acesso em: 1 ago. 2020.

SATO, Masayuki. A Social History of Japanese Historical Writing. In: SATO, Masayuki; RABASA, José; TORTAROLO, Edoardo; WOOLF, Daniel. The Oxford History of Historical Writing. Vol. 3, 1400-1800. Oxford: Oxford University Press, 2012. 
SEATON, Philip. Japan's Contested War Memories: The "Memory Rifts" in Historical Consciousness of World War II. New York; London: Routledge, 2010.

SENDA, Kakou. Jügun-ianfu [Mulheres de Conforto dos Militares]. Tokyo: Futabasha, 1973.

SHIMONO, Ikkaku. Nankin sakusen no shinso: Kumamoto Rokushidan senki. [A verdade sobre a operação Nanjing: Kumamoto $6^{a}$ Divisão Senki] Tokyo: Tokyo Information Company, 1966.

TANAKA, Yuki. Japan's Comfort Women. London: Routledge, 2001.

TANAKA, Yuki. Shira rezaru senso hanzai - nippongun wa ōsutoraria hito ni naniwoshita ka [Crimes de guerra desconhecidos - o que exército japonês fez aos australianos]. Tokyo: Otsukishoten, 1993.

TANAKA, Yuki. The Atomic Bombing, the Tokyo Tribunal and the Shimoda Case: Lessons for Anti-Nuclear Legal Movements. In: TANAKA, Yuki; MCCORMACK, Tim; SIMPSON, Gerry (Orgs.). Beyond Victor's Justice? The Tokyo War Crimes Trial Revisited. Leida (NL): Brill, 2011. pp. 291-310.

TANAKA, Yuki; YOUNG, Marilyn B. (Orgs.). Bombing Civilians: A Twentieth-Century History. New York: New Press, 2009.

TIMPERLEY, Harold. What War Means: The Japanese Terror in China, a Documentary Record. London: Left Book Club, 1938.

VIDAL-NAQUET, Pierre. Os Assassinos da Memória: um Eichmann de papel e outros ensaios sobre o revisionismo. Campinas: Papirus, 1988.

YOSHIDA, Reiji. Asahi Shimbun Admits Errors in Past "Comfort Women" Stories. 5 ago. 2014. Disponível em: https://cutt.ly/YdGXuTh. Acesso em: 1 ago. 2020.

YOSHIDA, Seiji. Tokyo: Chōsen hito ianfu to nihonjin [Mulheres de conforto coreanas e o povo japonês]. Tokyo: Chūkeishuppan, 1977.

YOSHIDA, Seiji. Natasha no senos hanzai [Meus crimes de guerra]. Tokyo: San-Ichi, 1983.

YOSHIMI, Yoshiaki. Comfort Women: Sexual Slavery in the Japanese Military During World War II. New York: Columbia University Press, 2002.

\section{NOTAS}

${ }^{1}$ Texto original: "That's taboo, and few Japanese historians touch upon it. We cannot only protest that we are innocent victims of the bomb without atoning for the crimes that Japan committed. Tears that pour out for the victims of the atomic bombs must also be accompanied by prayers for those who feel victim to Japan's criminal acts during the war".

2 Título original: 従 軍 慰 安 婦(Jugun'ianfu).

${ }^{3}$ Título original: 朝 鮮人慰安婦と日 本人 (Chōsen hito ianfu to nihonjin).

${ }^{4}$ Título original: 私の 戦争 犯罪 (Watashi no sensō hanzai). 
${ }^{5}$ Texto original: "but it is clear that no one will benefit from a new round of heated historical debate. To avoid this, political leaders like de Gaulle and Adenauer are needed.”

${ }^{6}$ Texto original: "only when we can discuss the past without endangering the future will the countries of Northeast Asia be able to establish a truly durable structure of peace".

${ }^{7}$ De acordo com Pereira (2015), a memória traumática passa pelos regimes de "não-inscrição", "inscrição frágil” e "inscrição forte". De forma resumida, pode-se entender que esses regimes se estabelecem quando a memória sobre determinado evento é percebida e entendida socialmente com maior ou menor abrangência. No caso estudado, relativo à memória das ditas "mulheres de conforto", a partir das publicações de Yoshida, a sociedade japonesa passou a vivenciar com mais frequência os relatos de sobreviventes, de vítimas, os quais obtiveram espaço nos jornais, nas televisões, rádios e começaram a circular na arena pública. Isto demonstra que essa memória alcançou a condição de uma inscrição frágil, a qual se esvaiu algumas décadas mais tarde, quando a fraude de Yoshida foi revelada, momento em que a memória traumática japonesa em questão retorna à categoria de não-inscrição.

8 Título original: "Nankin Jiken”

Artigo submetido em 9 de janeiro de 2021.

Aprovado em 9 de março de 2021.

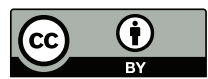

